\title{
Platform business Eco-model evolution: case study on KakaoTalk in Korea
}

\author{
Junghee $\mathrm{Han}^{1^{*}}$ and Okjoo $\mathrm{Cho}^{2}$
}

\author{
* Correspondence: \\ hjh0037@chonnam.ac.kr \\ ${ }^{1}$ Graduate School of Business, \\ Chonnam National University, Room \\ 304, Young Bong dong, Gwang Ju \\ City, South Korea \\ Full list of author information is \\ available at the end of the article
}

\begin{abstract}
Platform business is often regarded as notable examples of successful businesses model in the mobile industry. The purpose of this study is to find the determinants of successful platform business, through the case study of KakaoTalk, a representative fast growing social platform in Korea. This study also discusses how to create a value proposition and how organizations using the platform can cooperate.

The case analysis indicates that a preparation, spread, evolution (PSE) curve is a successful platform business evolution. The PSE curve is composed of three phases: a preparation phase that establishes the platform and sets the target group, a spread phase where the firm provides killer content, such as KakaoGame, a low pricing strategy, and reinforcement of the platform rules in the early stages of the platform; and an evolution phase where the platform continues to evolve. This study proposes a platform evolution pattern that involves the PSE curve in order to form successful platform. This study contributes to the innovation for social platform businesses.
\end{abstract}

Keywords: KakaoTalk; Business model; Business model innovation; Platform; Korea

\section{Background}

Over the last ten years, unprecedented growth in social network services (e.g., Facebook) has greatly increased the use of platform business models. In addition, the increase in smartphone penetration has led to a battle among platforms. The mobile revolution was triggered by the introduction of Apple's iPhone, and since then, the business environment around such platforms has brought about increased competition. The emergence of new information and communication technologies (ICT) and of the Internet have opened new opportunities to design open market business models by enabling companies to fundamentally change how they organize and engage in economic exchanges both within and across companies as well as through industry boundaries (Zott and Amit, 2007). In Korea, the mobile Internet environment has flourished in the last ten years, and as a result, social platform enterprises and app stores are growing rapidly. KakaoTalk is the provider of a mobile messaging application and mobile social platform in Korea. Since KakaoTalk, launched in 2010 as Mobile Instant messenger (MIM), it has strongest position in the mobile industry, expanding its service beyond messaging to a social platform encompassing games, digital contents, marketing e-commerce and more. It has become key stone for the mobile industry growth in Korea by providing mobile platform ecosystem. KakaoTalk was chosen the No 1 free Short Messaging Service (SMS) App by CNET, an American media website that

(c) 2015 Han and Cho. Open Access This article is distributed under the terms of the Creative Commons Attribution 4.0 International License (http://creativecommons.org/licenses/by/4.0/), which permits unrestricted use, distribution, and reproduction in any medium, provided you give appropriate credit to the original author(s) and the source, provide a link to the Creative Commons license, and indicate if changes were made. 
publishes reviews, news, articles, blogs, podcasts and videos on technology and consumer electronics globally in 2011. KakaoTalk, leading in the mobile industry, and became an inseparable part of the lives of Korean users. Most smartphones users, regardless of gender and age, use KakaoTalk.

We pose research questions on how KakaoTalk could achieve huge success in Korea unlike other social platform enterprises. Based on research back ground, the purpose of this paper is to find determinants of KaKaoTalk's huge success, and describe the platform business model. By analyzing KaKaoTalk's business model, we find that PSE (Preparation, Spread, Evolution) curve, composed of three phases: the preparation phase that establishes the platform to set the target group; the spread phases where killer content is provided in the early stages of the platform, such as KakaoGame, a low pricing strategy, and reinforcement of the platform rules; and the evolution phase where the platform continues to evolve. KakaoTalk has vitalized the mobile game industry by collaborating with game developers to provide Kakao Game, while launching Plus Friend, a powerful mobile marketing channel for enterprises and content providers. In addition, KakaoTalk's Gift Shop, which allows users to send gifts like Starbucks coffee or fine jewelry to their KakaoTalk friends, has created a new window of opportunity in the mobile commerce market.

This paper is organized as follows. Section 2 presents the research methodology as well as reviews of the literature on business model. Section 3 describes the specific case involving KakaoTalk's platform business, and the findings are used suggest the determinants for success in order to derive the platform business as an ecosystem model. In the final section, we shed light on the evolution of platform business model in mobile industry.

\section{Literature review and research methodology Business model}

KakaoTalk providers a free software application for mobile devices that allows customers to send and receive messages and voice calls for free. Users can not only send texts, photos, videos, and contact information, but can also enjoy voice calls, all on a one-to-one basis or in groups. Before the finding of what KaKaoTalk's business model is, we review the business model.

Recently, some scholars have devoted a growing amount of attention to business model innovation (Teece, 2010; Najmaei, 2013). A business model articulates the logic and provides data and other evidence that demonstrates how a business creates and delivers value to customers (Teece, 2010). In short, a business model could be defined as the manner in which an enterprise creates and delivers value to customers, and then converts the payments that are received into profit (Björkdahl, 2009; Chesbrough, 2007; Zott and Amit 2010; Zott et al., 2011). No consensus exists yet regarding the definition, structure, and evolution of a business model. The manner in which firms create and capture value is a popular research topic. Each firm has its own business model, but no generally-accepted definition of the term 'business model' has yet emerged. Prior studies regarding business models fail to reach a consensus to define their components. The interest in business models is relatively recent, and Boudreau (2010) noted that early work to identify business models focused on capturing the revenue stream of web-based firms. No matter the sector, there are criteria that enable one to determine 
whether or not one has designed a good business model. Business models yield value propositions that are compelling to customers, achieve advantages in terms of the cost risk structures, and enable significant value to be captured by the business.

At the most rudimentary level, business models are defined in terms of a firm's economic model (Morris et al., 2005). The business model concerns the logic of how profit is generated by the firm. Steward and Zhao (2000) assert that the business model is a statement of how a firm will both make money and sustain its profit stream over time. Furthermore, the business model can be defined as an architectural configuration of the firm's survival. Slywotsky (1996) noted that a business model consists of the totality of how a company selects its customers, defines and differentiates its offerings, defines the task it will perform itself and those it will outsource, configures its resources, goes to market, creates utility for customers, and captures profits. A business model is related to a number of other managerial concepts, and it captures the key components of a business plan. The business model components consist of price, product, distribution, organizational characteristics, and market strategy (Horowitz, 1996; Timmers, 1998; Dubosson-Torbay et al., 2001; Hamel, 2001). What do we know about a business model? Prior studies are referenced in this study to define the business model of a company as a simplified representation of its business logic. Namely, a novel business model is crucial to maximize profits. It is called multi side platform business model like KaKaoTalk. Multi-side platform is widely known for customers, and plays a role to link or broke between the interdependent groups, based on web and smartphones. AirBnB is the firm, operating to link between groups that want to find houses and groups that want to lend a house. Thus, the both supply side and demand side is the key composing the market. Amazon, Facebook, E-bay, twitter, Google and apple is the successful firms by using the multi-side Platform business model.

\section{Conceptualization of platform}

The role of a platform is to mediate between various stakeholder constituencies by coordinating interactions between two or more members from distinct groups of stakeholders (Evans, 2003; Rochet and Tirole, 2003; Jullien, 2005; Cortade, 2006).

Jacobides et al. (2006) emphasized that a platform creates value and is an important structure of the industry architecture in the ICT sector. Also, a platform in the ICT sector can be referred to as a hardware configuration, an operating system, a software framework or any other common entity shared by users (Ballon et al., 2008; Bresnahan, 1999). Gawer and Henderson (2007) state that we can conceptualize a platform as a technological system where a product or service is one component that is functionally interdependent with other components. Thus, a platform provides a number of benefits to its users. As a result, user demand is for the overall system, and hence, there is no demand for individual components when they are isolated from the overall system (Gawer and Henderson, 2007).

A platform-mediated network is a composite set of users whose transactions are subject to direct and/or indirect network effects, along with one or more intermediaries that facilitate users' transactions (Rochet and Tirole, 2003; Evans and Schmalensee, 2007). From the literature, we can induce that a platform is the set of components and rules that are commonly employed when users conduct transactions. Such components 
include hardware, software, and service modules, along with an architecture that specifies how they fit together.

In such a market, the value obtained by one customer group increases as the number of users from the other customer group increases (Evans, 2003). This phenomenon is described as a network externality, for which consumption by one side of the market does not depend on the same group, but on the opposite side of the market (Roson, 2005). A buyer takes into account the number of potential sellers on the platform when making a purchase. Evans (2003) pointed out that an intermediary is necessary to internalize the externalities created by one group for the other group. In economics, this kind of behavior between two markets is regarded as an indirect network effect of two-sided markets.

A successful platform coordinates the interaction between individuals belonging to various stakeholder groups, and it is also able to internalize the externalities created by one group for the other group. A platform business model, thus, needs to get various stakeholder groups on board and needs to balance the interests of these groups by focusing on balancing the openness and lock-in of customers rather than on profit maximization in a single market (Cortade, 2006; Ballon et al., 2008). Technology platforms are two-sided or multi-sided markets that bring together various types of participants (Rochet and Tirole, 2003). Unless a business serves two or more distinct types of customers who depend on each other in some form, it is not platform. When various types of customers interact with each other, then it is called a platform. Prior to reviewing platforms in greater detail, we can conceptualize the function of a platform as follows: a platform is 'open' to the extent that no restrictions are placed on participation during its development and/or utilization.

Platform-mediated networks are comprised of entities that play several distinct roles, including demand-side platform users, commonly referred to as 'end users.' Supply-side platform users offer complementary participation and are employed by demand-side users by using the core features of the platform. The platform provider serves as a user's primary point of contact on the platform. Platform sponsors exercise property rights and are responsible to determine who may participate in a platform-mediated network and who may develop its technology. For a given platform, each of these roles may either be open or closed. Consequently, a platform can be characterized by its openness. Eisenmanne et al. (2008) related a platform to a business model. Eisenmann et al. (2008) considered a platform business to be a platform-mediated network. Figure 1 shows that a platform-mediated network is composed of demand-side users, supplyside users, platform providers, and platform sponsors.

The transactions between the demand-side users and the supply-side users, which are likely a result of the network effect, are facilitated by the intermediary's role in providing the platform and recruiting platform sponsors.

\section{Methods}

The goal of this study is to find successful the social platforms by analyzing KakaoTalk as a representative example as well as to propose the evolution of the platform business model. KakaoTalk has created the dominant platform business market in Korea, and it has tremendous influence on entrepreneurs within the app ecosystem. Fieldwork and field interviews were carried out to obtain raw data. When the targets were selected for 


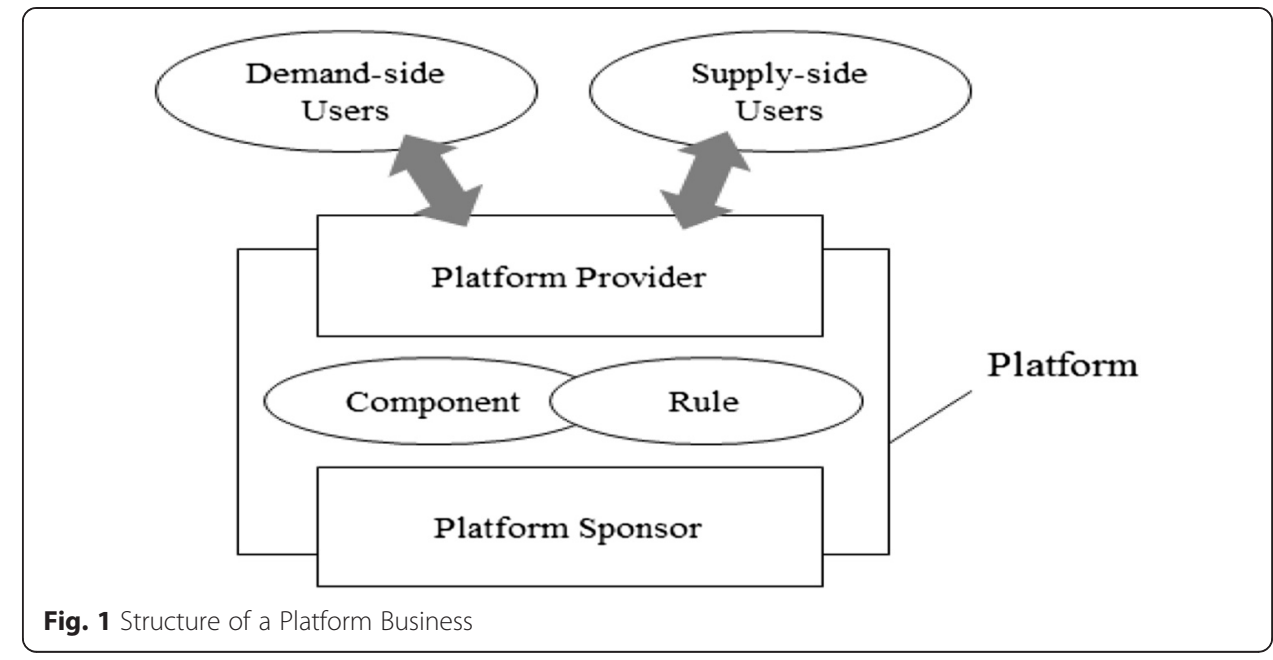

the intensive interviews, a purposive sampling question was adopted in order to identify interviewees, including their individual characteristics. This method is particularly effective and appropriate for this type of qualitative research (Punch 1998). Before contacting the individuals in person, it was necessary to scrutinize the details of data released by secondary sources, such as turnover, brief history, and CEO's creed and former achievements. In particular, the information released by newspaper was thoroughly examined before having an interview and academic journals and periodicals were also analyzed.

Due to firm policy, which has a strong emphasis on internal security, it takes time to meet experts related to business model development, including the CIO of KakaoTalk, by proving that the purpose for such contact involves academic research aims. In order to effectively implement the case analysis, the data was collected from KakaoTalk's intranet information, various data released in newspapers, in-person interviews with developers, and several in-depth discussions with relevant parties. To further improve the quality of the research quality, interviews with App developers and KakaoTalk users were also carried out over a period of 5 months. To gain further insight into the academic process for formulating and analyzing business models, the author used a standard interview format with the CIOs or founders of such companies. Most of the interviews were recorded with the consent of the interviewees, including those interviews conducted over the phone.

\section{Results}

\section{Business summary}

As social platform provider, KaKaoTalk offers a wide range of content and services including business marketing, commerce, games, digital content, fashion and music. KaKaoTalk has more than 150 million registered users including the across the world. Messages are delivered in 15 languages, on Android iOS, BlackBerry, Windows Phone, and NoKia Asha. Since 2010, KaKaoTalk, offering a mobile social platform has rapidly grown. When considering the increase ratio of users, KakaoTalk' users reached 10 million users only over 1 year 2011, 42 million in 2012 years, and more than 150million users after 3 years. Kakao Inc., which provides the KakaoTalk service, launched several internet- 
based services. At the initial stage, Kakao's CEO, Kim BumSoo launched 'buro.com' and 'wisia.com' with the goal of achieving user-oriented evolution, but both of these services failed to get the attention of users. After Kakao had captured customers using its free messenger service, the users were then absorbed into 'Kakao Game.' Next, the company created platform value by linking game operators and developers. This strategy was effective, and it greatly affected the domestic mobile game market, for which the market size increased from 20 billion to 800 billion won as a result of Kakao Game. Since then, Kakao has continued to expand its platform by providing a mobile shopping mall called Kakao Style and has also provided further social SNS features through Kakao Story. Most of Kakao's profits are in the form of brokerage fees and ad sales in game-related businesses. Google and Apple receive a $30 \%$ commission of the total game sales, and Kakao gets $30 \%$ of the remaining $70 \%$ commission. A considerable number of Kakao games offer inapp purchases, which means that they make profits by selling useful items in the process of playing the game, while the games are offered for free. Kakao matches a broker's fees for game items and gifts to sales. This is the typical platform business strategy: the more games that become popular on the Kakao game platform, the more Kakao's profits rise. Kakao's revenue reached 46.2 billion in 2012, with total sales of 1 trillion won. KakaoTalk can take the lead the mobile game industry by collaborating with game developers to provide Kakao Game, while launching Plus Friend, a mobile marketing channel for firms and content providers. In addition, KakaoTalk's Gift Shop, which allows users to send gifts like Starbucks coffee or fine jewelry to their KakaoTalk friends has a play role to create a new social commerce market. The Item Store market, which sells emoticons, is also important success ingredients, representative win-win business model that has contributed to the revival of the digital content market, as profits are shared fairly with the content creators. In additions, KakaoTalk brings about new paradigms to the mobile contents market via KakaoPage, a new form of mobile digital contents platform, while KakaoMusic has established a distinctive social music service where users can share their favorite music with friends. Kakao also already have a positioning as a global mobile platform, Kakao continues to secure its position as an important benchmark and industry pioneer in the global community. KakaoTalk has been recognized worldwide by influential organizations, winning the Red Herring Asia Top 100 Award in 2012, and nominated as finalist for Global Mobile Awards most Innovative App in 2014.

\section{Business platform}

"We want to make the platform to earn the money," said Kim BumSoo, the CEO, at the press conference. He emphasized platform. He defined the platform system as an opportunity for partners to make money. The concept of platform has been used over a long period of time in a variety of fields such as a stock exchange, department stores, and magazines. Recently, however, the rapid development of technology and the acceleration of digital convergence have come into the spotlight (Lim, 2012) (Table 1).

When building the platform, the first consideration is to make a decision to provide some value in some industry. The most successful platforms have a common ground in that they appear when there are social changes or changes in lifestyle. When we want to create a successful platform, it is very important to have an understanding of large flows of social change since there is likely to be no existing platform or there will be few successful cases when a new lifestyle appears. Even today, many industries have 
Table 1 KaKao mobile platform

\begin{tabular}{|c|c|c|c|}
\hline Platform & Service & Partners of mutual growth & Details \\
\hline \multirow[t]{2}{*}{$\begin{array}{l}\text { Mobile } \\
\text { Commerce }\end{array}$} & Gift Store & $\begin{array}{l}\text { Mobile coupon companies } \\
\text { and other partners }\end{array}$ & $\begin{array}{l}\text { - Creates new opportunities for the mobile } \\
\text { commerce market and generates new } \\
\text { consumption trends that lead to m-commerce } \\
\text { vitalization }\end{array}$ \\
\hline & KakaoStyle & Online fashion malls & $\begin{array}{l}\text { - A new mobile shopping channel that connects } \\
\text { Korea's Soho fashion malls with KakaoTalk users } \\
\text { (note: I have not been sure what 'Korea's Soho } \\
\text { fashion malls' has been describing - the unique } \\
\text { style of Korean boutique fashion perhaps? Is it } \\
\text { specifically connecting brick and mortar stores to } \\
\text { mobile shoppers? Could be my cluelessness...) }\end{array}$ \\
\hline \multirow[t]{2}{*}{ Marketing } & \multirow[t]{2}{*}{ Plus Friend } & \multirow{2}{*}{$\begin{array}{l}\text { Corporate/product brands, } \\
\text { social welfare organizations, } \\
\text { celebrities, media, etc. }\end{array}$} & - A new advertising model optimized for mobile \\
\hline & & & $\begin{array}{l}\text { - A customer-targeted marketing platform that } \\
\text { brings maximum efficiency to both customers } \\
\text { and advertisers }\end{array}$ \\
\hline \multirow[t]{4}{*}{ Contents } & \multirow[t]{2}{*}{ Game } & \multirow[t]{2}{*}{$\begin{array}{l}\text { Small- and mid-sized game } \\
\text { developers }\end{array}$} & $\begin{array}{l}\text { - World's first mobile game platform based on } \\
\text { social networking that strives for joint growth } \\
\text { with small mobile game developers }\end{array}$ \\
\hline & & & $\begin{array}{l}\text { - First Kakao service that has proved the power } \\
\text { of Kakao's platform }\end{array}$ \\
\hline & KakaoPage & Content creators & $\begin{array}{l}\text { - World's first mobile content distribution channel } \\
\text { where anyone can create and market their } \\
\text { original content }\end{array}$ \\
\hline & KakaoMusic & $\begin{array}{l}\text { Record companies, Entertainment } \\
\text { agencies, Copyright holders }\end{array}$ & $\begin{array}{l}\text { - Social music service of a new concept of sharing } \\
\text { and communicating with friends through music }\end{array}$ \\
\hline
\end{tabular}

Source: Revised KakaoTalk 2014 report

entered a mature stage, so there are new changes happening somewhere else, and opportunities are created when there are changes (Hirano and Andrei, 2011).

Upon the iPhone was launched in Korea at the end of 2009, Kim Bumsoo, CEO of KakaoTalk predicted a mobile revolution and noted that communication was a key value of the mobile space. "What is a phone? A phone is for calling. What is a killer app on your phone? Either calling or sending a text message. Then we did not have to hesitate. A communication tool is the killer app, otherwise a search tool is the most important tool for a personal computer. The essence of a phone is communication. Finally, we launched KakaoSuda, KakaoAgit, and KakaoTalk." That is, he understood the fundamental attribution of mobile as tool for communication, and he tailored it to meet the needs of customers suited to their lifestyle. In brief, he realized that the attribute of a mobile phone could be delivered through the KakaoTalk service. He replaced an existing tool within phones that was being offered as a paid service and replaced it with KakaoTalk, which was a free service delivered over the Internet. This also improved communications.

Despite having launched one year in advance, Google Hangouts (then called Google Talk) had a weakness in that user registration was incovenient. Google Talk users were required to directly register as members and other members also had to register for the service. So people felt uncomfortable with this demand, and so Google Talk failed to gain many users.

KakaoTalk took advantage of this weakness in the process required by Google Talk by implementing a convenient automatic registration rule for users. If you download the KakaoTalk application, you can easily use free mobile instant messaging service without 
registration procedures, such as those required by Google Talk. After that, it dominated the market by advancing in the market and developing more quickly that its rivals, Mypeople and Line. As a result, KakaoTalk created a new platform for mobile instant messaging that replace the paid messaging services provided by mobile carriers (Chang and Oh, 2013).

According to the interview data, Platform also become the 'place' essentially indicates where some activity takes place. Finally, a platform business produces a variety of exchanges where a seller and a buyer meet. In an early stage, KaKao try to find how to increase the satisfaction. Smartphone users desired to have a new style of communication when KakaoTalk came into the market. KakaoTalk is helpful for having conversations and to build a network, so it is possible to have one-to-many communication and to review past conversations. Furthermore, we can use emoticons to express various feelings. KakaoTalk is a fresh platform where users can check whether a message has been read, and in addition, photos and profile names can be used within KakaoTalk, and many users are attracted to the platform due to these features.

\section{Interactive system and killer contents}

In the Platform, more important thing is to create the interactive system not leaving the platform. If the platform has attractive contents, so called killer content, we can with ease establish interactive system such as, a strategic alliance with other companies that have different content, and the platform can be built together. At first, KakaoTalk was a messenger service that provided only text. Since then, the number of users on KakaoTalk has quickly increased, amplified by the fact that it is a free service. As a result, the company has built a self-centered ecosystem. Kakao Inc. now offers KakaoGame, KakaoPage, KakaoStyle, etc. to provide game and content services; KakaoFriends, gift, itemstore, etc. to provide marketing services; and KakaoTalk, KakaoStory, etc. have been expanded within social networking offerings. The business structure of Kakao matches up against that of a mobile platform to expand and develop the business model based on subscribers and to build an ecosystem to lead the industry (Kim, 2013) (Table 2).

To be successful, a platform provides the right content to its users, and a platform can be more competitive by bundling services in order to further engage consumers with killer content.

As the mobile industry began to grow, Iwilab, the prior name of Kakao, simultaneously released KakaoSuda, KakaoAgit, and KakaoTalk as mobile services, but they all initially failed. The value that KakaoTalk provided to customers as a free messenger service then became clear, and it provided the momentum needed to secure customers. At the beginning, the free messenger service was the killer content provided by KakaoTalk. After 2010, Kakao also began to offer the Gifticon and Choco services. Since then, the company has bundled other services, such as an emoticon service and KakaoStyle, and has expanded its business activities to games, fashion, business marketing, digital content, etc. KakaoGame then became the killer service provided by KakaoTalk that provided further rapid growth. KakaoGame basically provides a social network for games, which is a new type of service for games to blend gaming and social network service (SNS) features to build online connections, such as that also provided by Facebook. Existing games use network technologies to enhance the enjoyment provided by the game itself. However, social network games use the game to provide a further sense of closeness between the 
Table 2 Service of Kakao

\begin{tabular}{|c|c|}
\hline & Content \\
\hline KakaoTalk & $\begin{array}{l}\text { Social networking service that provides chat and voice services (voice talk, group call) between } \\
\text { groups and 1:1 }\end{array}$ \\
\hline KakaoStory & Social networking service to share photos and private events between users \\
\hline KakaoMusic & Service to listen to music using the smartphone \\
\hline KakaoGroup & $\begin{array}{l}\text { Social networking service to share photos and private lives in a group chat with a number of } \\
\text { group members }\end{array}$ \\
\hline KakaoHome & Service to help users decorate and add character to the home screen of their smartphone \\
\hline KakaoPlace & $\begin{array}{l}\text { Location-based social networking service to share the popular restaurants and attractions } \\
\text { between KakaoTalk friends }\end{array}$ \\
\hline KakaoAlbum & Mobile photo share service to collect photos taken by friends in one place \\
\hline KakaoPage & Mobile marketplace to buy, sell, and share music, videos, e-books and other digital content \\
\hline KakaoStyle & Social network service to see the hottest fashion in one place and to share it with friends \\
\hline KakaoAgit & Service to get together and to share photos, videos, music, etc. between close friends \\
\hline KakaoGame & Mobile game platform to compete with Kakao friends \\
\hline KakaoAccount & One account to explore all of Kakao's apps and linked services through email \\
\hline KakaoLink & Service to send links from external apps or mobile webpages to KakaoTalk and KakaoStory \\
\hline
\end{tabular}

Source: Revised KaKaoTalk 2014 report

users. Online games can possibly invite bad behavior, such as when players use swear words. However, users feel intimacy with each other in KakaoGame, and this closeness can minimize the negative behaviors in online games. KakaoTalk has remained the market leader by providing killer content that combines both game and SNS features.

The pricing strategy depends on the relationship of the dynamics between the platform provider and the participants, the attachment of the group to the platform, and the competitive environment. Therefore, a platform provide must adjust prices flexibly according to a variety of conditions and must also carefully observe market trends and the responses of participants.

Whats App is the world's largest mobile messenger app, and it merged with Facebook for a price of 16 billion dollars. As of August 2013, the traffic handled by the company included 31 billion message transfers in a day. The company has focused on providing a simple and easy-to-understand service without advertisements by charging a $\$ 0.99$ an annual fee instead. This service has kept to its original function as a messaging service (Han, 2013).

On the other hand, users do not pay to use the messenger service provided by KakaoTalk. The KakaoTalk users only pay when they buy items from the emoticon service, Gifticon, and KakaoGame. As we consider the revenue figure, kaKaoTalk has marked 348 billion Won (\$311 million) in revenue during the first year of the launch of its mobile game services. That's an impressive 194 percent from the final quarter of 2012, when the platform grossed 118 billion Won (\$105 million). Total sale is 8,984 billion won in 2014 . When it comes to the number of users, KaKaoTalk is 3094 million, $87.8 \%$, and over overwhelmingly dominant the mobile messenger market as of 2015.

Although KakaoTalk tried to make profits from the Gifticon and emoticon services, it did not achieve the expected results. However, KakaoGame, which launched in July 2012, has become a huge game platform and has changed the dynamics of the domestic gaming market. Starting with Anipang and Dragonfly, KakaoGame quickly attracted 
KakaoTalk users into KakaoGame. This means that KakaoTalk's 60 million users have contributed to the growth of the service (Choi et al. 2014).

The revenue strategy for Kakao is to embody various forms of content as a distribution platform, not just for mobile advertising (Han, 2013). "Portals are used to rushing into a market or taking over the company when the market grows up, but Kakao will be faithful to our role of assisting other enterprises," This shows that Kakao differs from portals that devastate the ecosystem and concentrate on turning a profit.

\section{Strategy for 'evolution and utilization of open innovation}

The platform must always evolve in order to survive because the transition towards new platforms is quite common. The important fact to remember is to not lose perspective, namely, the original desire of the group to participate in the platform. In order to do that, we must consistently ask why this platform exists as well as when, who, what, where and how this service or product are used. KakaoTalk has evolved through a three-step process Step 1 consists of the introduction phase to expand its subscriber base. KakaoTalk rapidly increased the number of its subscribers as the dominant free messaging service in the Korean market. In Step 2, KakaoTalk attempts to launch a variety of social services. KakaoTalk was confident in the release of KakaoStory, etc., and the company evolved its service to the next step. In Step 3, KakaoTalk evolves from an SNS service to a social media company that provides a social platform. KakaoTalk already provides media, like movies, fashion, employee-related news and contents within the culture and media category of the KakaoPlus service. This feature is similar to the one-to-many communication service provided by Twitter, and we can interpret KakaoTalk to be at the beginning of providing social media (Jung, 2012) (Table 3).

Those who are related to KakaoTalk, such as external developers, internal staff, and users, described Open Innovation as a common strategy for success. KakaoTalk itself does not create content, such as Facebook and Twitter. External participants create a variety of content, and KakaoTalk is only responsible to opearte the platform. Therefore, KakaoTalk can expend minimal manpower for development, and it has a competitive edge by concentrating on its core activities. In a mobile ecosystem, there are more disadvantages than advantages to monopolize content with internal staff, such as how Naver operates. On the other hand, it has a great advantage in that it provides both speed and quality for parties to supply content from outside the platform.

In this study, we find that the PSE curve is a unique feature in KakaoTalk's platform. During the prepreation, in other words, the platform formation stage was to be defined

Table 3 The evolutionary process of KakaoTalk

\begin{tabular}{lll}
\hline Step 1 & Step 2 & Step 3 \\
\hline The early stage of the SNS & The growth stage for the & Evolution toward social media and a platform \\
& SNS company & \\
-Ensuring social services through & $\begin{array}{l}\text {-Trying a variety of social } \\
\text { service }\end{array}$ & -Providing media channels in KakaoPlus \\
user expansion & -Photo based KakaoStory, \\
& game marketing platform & -Expanding influence as a media platform \\
& KakaoGame, etc. & -Trying to be a social platform with avatars, \\
& app stores, advertising and commerce \\
\hline
\end{tabular}

(Source: Jung, 2012) 
the target group for the interactive system. During the spread stage, KakaoTalk rapidly grew by utilizing KakaoGame's so-called killer content. In order to get quickly grow its user base, the services and content were bundled as a key feature. In addition, the pricing strategy had a great influence in attracting customers during the spread stage. In the final evolution stage, it is necessary for the platform to continue to evolve in order to maintain constant growth. These three stages offer the opportunity for the platform business to become sustainable. That is, our findings indicate that applying the PSE curve provides an advantage over late movers. KakaoTalk has actively conducted these strategies, and it has therefore dominated the domestic mobile instant messaging market (Fig. 2).

This study has determined the success factors that are relevant for a business platform by conducting research and interviews with many stakeholders. These success factors suggest a new business platform model. Figure 6 depicts the business model that corresponds to such an eco-system. When a new business platform starts, it is important to set up a domain and the target groups, and then a proper pricing strategy is essential. To operate efficiently, platform business enterprises should establish an interactive system that allows activity with different platform elements. Killer content are a precondition for platform growth.

A useful method to develop a new product or service is to secure killer content. At this stage, interested parties (users, platform members, and the platform provider) interact with each other in many ways, and this solidifies the success factors that will lead to success for the business platform. Through these stages, a platform becomes ready to evolve. A platform constantly evolves through interactions with internal and external members of the platform. Finally, an eco-system between the members belonging to the system (platform members, users, platform provider) is established, and a virtuous circle begins to operate. In this complete system, a business platform model for an eco-system is organically formed (Fig. 3).

\section{Discussion and conclusions}

KakaoTalk can be able to grow rapidly as a result of the quick use of unique platform strategies. This study performed a case analysis of KakaoTalk to find the determinants of successful social platforms as well as to determine how to create a value proposition

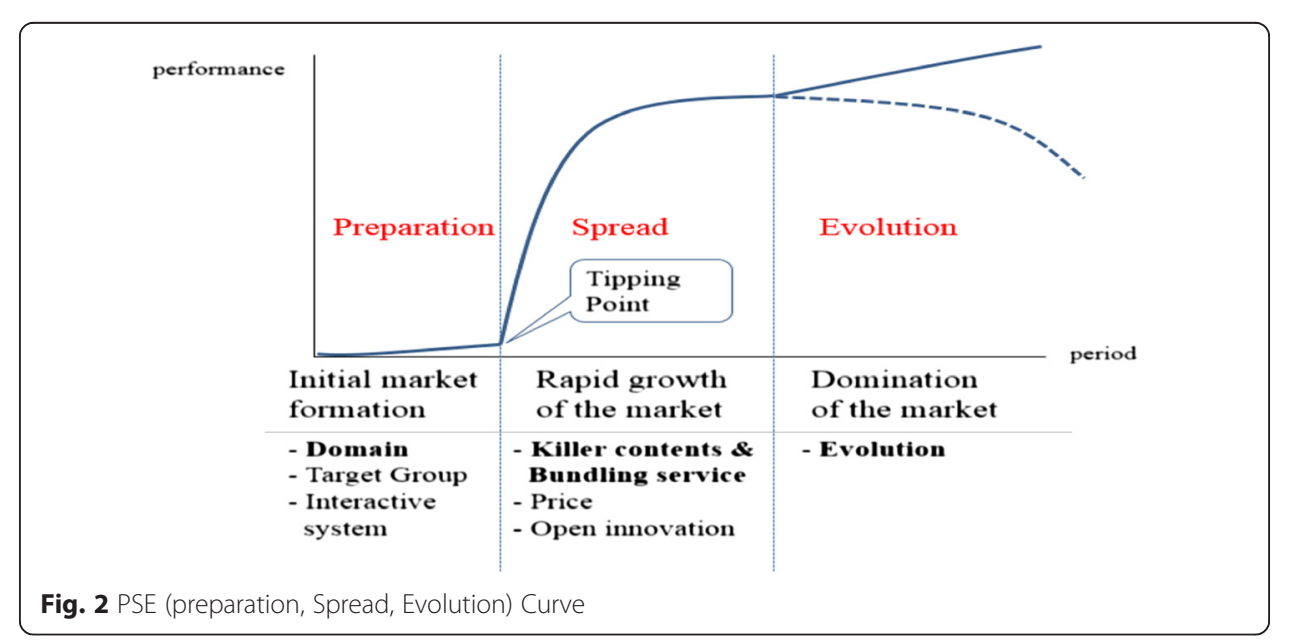




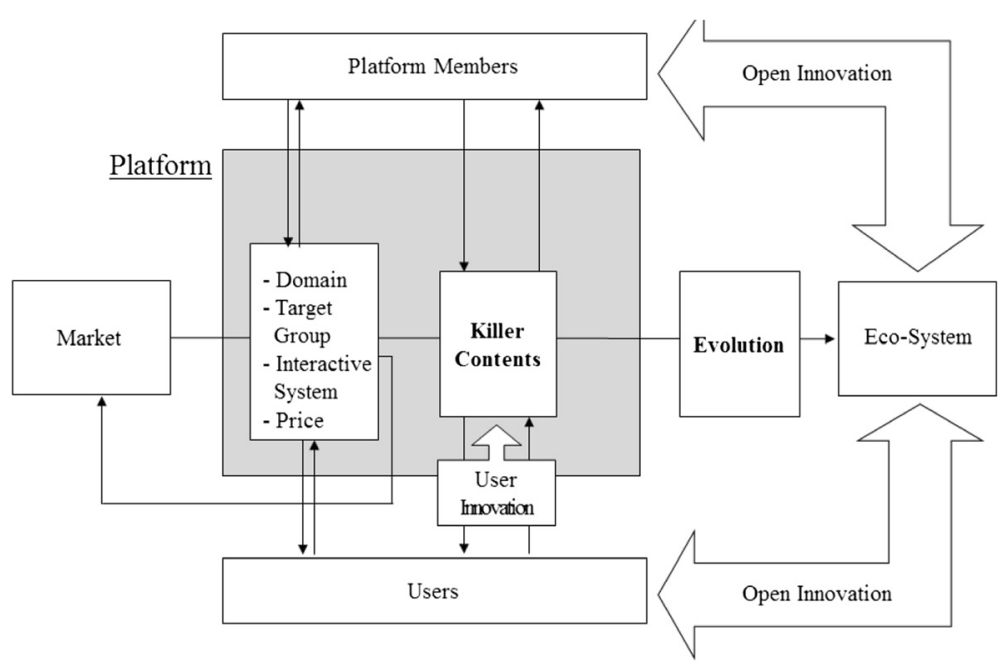

Fig. 3 Business Platform Model for Eco-system

and how organizations in the platform can cooperate. The goal of the research is to suggest a platform business model that is useful for building eco-systems. In order to fulfill these research aims, this study utilized direct data related to KakaoTalk as well as discussions and interviews with the $\mathrm{CIO}$ at KakaoTalk and other stakeholders.

These findings reveal that in the first stage, KakaoTalk created a mobile instant messenger within a new domain. In the second stage, existing mobile users who were searching for new means of communication were obtained. In the third stage, KakaoTalk grew rapidly by providing a free service and further expanded its business to the marketing and social domains. In the fourth stage, KakaoTalk decided to continue to offer free text transmissions as a killer service, and the company expanded its range of services to games, fashion, business marketing, digital contents, etc. by bundling services. In the fifth stage, KakaoTalk redefined its business not only as a simple mobile messaging service but also as a distribution platform and began to provide a wider variety of content. In the sixth stage, KakaoTalk underwent three evolutionary stages including an early stage as an SNS Service, growth stage as an SNS company, and evolutionary stage as a social media platform. In the seventh stage, KakaoTalk actively engaged in open innovation.

KakaoTalk is the mobile instant messenger that the vast majority of Korean smartphone users constantly use, and Kakao developed this app as its core platform and has provided a variety of follow-up platforms, such as mobile commerce, mobile advertisement, mobile games, etc. Continuous user interaction is necessary for the company to continue to be successful as a platform business. In other words, an open innovation strategy is also required to ensure business model evolution.

Finally, the findings of the case analysis suggest that the PSE curve is a unique pattern of the success of a social platform business model. The PSE curve is comprised of three faces: a preparation face that establishes a platform to set the target group; a spread face where killer contents are provided in the early stage of the platform, such as KakaoGame, a low pricing strategy, and reinforcement of the platform rules; and an evolution face where the platform continues to evolve. In addition, we have created a business model for a platform provider to build an eco-system by using the PSE curve to achieve success. In this paper, we find the successful path of platform business model, and suggest the eco- 
model evolution. What KaKao can evolve from simple mobile message to SNS platform in the first in the world is to find new value for customers using killer contents instead of seeking a business. Through this study, we find PSE (preparation, spread, evolution) curve.

The results of this study are subject to some limitations, but they also offer significant findings in that they provide the basics of an academic analysis of the factors that lead to the success of a platform. Further study is planned to address the merger of mobile messengers and this research can contribute to the mobile platform strategies in the future.

Competing interests

The authors declare that they have no competing interests.

\section{Authors' contributions}

$\mathrm{JH}$ and $\mathrm{OC}$ devote substantial contributions to research conception and design, and/or acquisition of data, and/or analysis, measure and interpretation of data, and authors participate in drafting the article and revising it critically for important academic content. Also all authors read article and give final approval of the version to be submitted and any revised version.

\section{Authors' information}

Junghee Han is a Professor of Management of Technology Program (MOT), at the Business School of Chonnam National University in Korea. He obtained his PhD in Business Administration at Seoul National University in 2008. He specializes in intellectual property, rights, technology commercialization, entrepreneurship, business model, innovation firm dynamic, and innovation policy. His primary interested research area is technology commercialization and innovation. Okjoo Cho is a manager of Technology commercialization Team in Chonnam National University. He obtained his Masters in Management of Technology (MOT) from Graduate School of Business, Chonnam National University, Korea. He has over 10 years of experience in the field of Technology commercialization.

\section{Author details}

${ }^{1}$ Graduate School of Business, Chonnam National University, Room 304, Young Bong dong, Gwang Ju City, South Korea. ${ }^{2}$ A Staff in Chonnam National University, OkJoo Cho, Gwang Ju City, South Korea.

Received: 1 June 2015 Accepted: 31 July 2015

Published online: 08 September 2015

\section{References}

Ballon P, Walravens N, Spedalieri A, Venezia C. The reconfiguration of mobile service provision: Towards platform business models. Promoting New Telecom Infrastructures: Markets, Policies and Pricing. 2008;2010:197-215.

Björkdahl J. Technology cross-fertilization and the business model: the case of integrating ICTs in mechanical engineering products. Res Policy. 2009;38(9):1468-77.

Boudreau K. Open Platform Strategies and Innovation: Granting Access versus Devolving Control. Manage Sci. 2010;56 (10):1849-72

Bresnahan T. New modes of competition: Implications for the future structure of the computer industry. In: Competition, Innovation and the Microsoft Monopoly: Antitrust in the Digital Marketplace. Boston: Kluwer Academic Publisher; 1999. p. 155-208.

Chang GY, Oh JS. A Study on Platform Strategies of Korean First Mobile Instant Messenger KakaoTalk. Asia-Pacific J Bus Venturing and Entrepreneurship. 2013;8(4):49-56.

Chesbrough H. Business model innovation: It's not just about technology anymore. Strategy Leadersh. 2007;35(6):12-7.

Choi, B. S, et al., (2014). Platform changes the Business Management: The success strategy found in the greatest platform company in this age. Samsung Economic Research Institute, 7-24.

Cortade T. A strategic guide on two-sided markets applied to the ISP market. Commun Strateg. 2006;61(1):17-35.

Dubosson-Torbay M, Osterwalder A, Pigneur Y. E-business model design, classification and measurements. Thunderbird Int Bus Rev. 2001:44(1):5-23.

Eisenmann T, Parker G, Van Alstyne M. Opening platforms: How, when and why? In: Platforms, Markets and Innovation. UK: Edward Elgar Publishing; 2008. p. 131-15.

Evans DS. The Antitrust economics of multi-sided platform Markets. Yale J Regul. 2003;20(2):325-82.

Evans DS, Schmalensee R. The industrial Organization of markets with Two-sided platforms. Issues on Competition Law and Policy, W.D. Collins ed; 2007;667-74.

Gawer A, Henderson R. Platform owner entry and innovation in complementary markets: Evidence from intel. J Economics Manage Strategy. 2007;16(1):1-34.

Hamel G. Leading the revolution. Boston (MA): Harvard Business School Press; 2001.

Han, EY. Global Mobile Messenger Service Competitive Strategies and Prospects. Korean Information Society Development Institute. 2013;25(16):1-46.

Hirano C, Andrei H. Platform Strategy: Who takes the place, dominate the future. Seoul: The Forest Press; 2011.

Horowitz AS. The real value of VARS: resellers lead a movement to a new service and support. Mark Comput. 1996;16 (4):31-6. 
Morris M, Schindehutte M, Allen J. The entrepreneur's business model: toward a unified perspective. J Bus Res. 2005;58 (1):726-35.

Jacobides MG, Knudsen T, Augier M. Benefiting from innovation: Value creation, value appropriation and the role of industry architectures. Res Policy. 2006;35(8):1200-21.

Jullien B. Two-sided markets and electronic intermediaries. CESifo Econ Stud. 2005;51(2-3):233-60.

Jung HS. The Evolution of Korean Social Network Service focusing on the Case of Kakao Talk. Digital Policy Res. 2012;10

(10):147-54

Kim MS. Case Study and Implications for the Evolution of Kakao as a Platform. Int Telecommun Policy Rev. 2013;25

(13):69-76.

Lim WG. Throw away Yesterday: Endless Challenge of Kim Bumsoo, Evolving Icon. Singapore: Dasanbooks; 2012

Najmaei A. How and why business model matters in acquisition of knowledge in small and entrepreneurial firms. In: Ndubisi N, Nwankwo S, editors. Enterprise Development in SMEs and Entrepreneurial Firms. Hersey, PA: IGI Global; 2013. p. 1-21.

Punch K. Introduction to Social Research. London: Sage; 1998.

Rochet JC, Tirole J. Platform Competition in Two-Sided Markets. J Eur Econ Assoc. 2003:1:990-1029.

Roson R. Two-sided markets: A tentative survey. Rev Netw Econ. 2005;4(2):142-60.

Slywotzky AJ. Value migration. Boston (MA): Harvard Business Review Press; 1996.

Steward DW, Zhao Q. Internet marketing, business models, and public policy. J Public Policy Mark. 2000;19:287-96.

Teece DJ. Business models, business strategy and innovation. Long Range Plann. 2010;43:172-94.

Timmers P. Business models for electronic markets. Electron Commerce Europe. 1998;8:1-6.

Zott C, Amit R. Business model design and the performance of entrepreneurial firms. Organization Sci. 2007;18(2):181-99.

Zott C, Amit R. Business model design: an activity system perspective. Long Range Planning. 2010;43(2):216-26.

Zott C, Amit R, Massa L. The business model: recent developments and future research. J Manage. 2011;37(4):1019-42.

\section{Submit your manuscript to a SpringerOpen ${ }^{\circ}$} journal and benefit from:

- Convenient online submission

- Rigorous peer review

- Immediate publication on acceptance

- Open access: articles freely available online

- High visibility within the field

- Retaining the copyright to your article 